\title{
Association of acute hepatitis a and brucellosis in two cases
}

\author{
Mehmet Selçuk Bektaş ${ }^{1,3,}$, Fesih Aktar ${ }^{2,3}$, Avni Kaya ${ }^{3}$, Hayrettin Temel ${ }^{3,4}$, Muhammed Akıl ${ }^{3,5}$ \\ ${ }^{1}$ Lokman Hekim Van Hospital, Van, Turkey \\ ${ }^{2}$ Diyarbakir Obstetrics and Children Hospital, Diyarbakir, Turkey \\ ${ }^{3}$ Department of Pediatrics, Yuzuncu Yil University Faculty of Medicine, Van, Turkey \\ ${ }^{4}$ Gebze Fatih State Hospital, Kocaeli, Turkey \\ ${ }^{5}$ Siverek State Hospital, Sanliurfa, Turkey
}

\section{Email address:}

selcukbektas008@gmail.com (M. S. Bektaş)

\section{To cite this article:}

Mehmet Selçuk Bektaş, Fesih Aktar, Avni Kaya, Hayrettin Temel, Muhammed Akıl. Association of Acute Hepatitis a and Brucellosis in Two Cases. American Journal of Clinical and Experimental Medicine. Vol. 2, No. 1, 2014, pp. 1-3.

doi: $10.11648 /$ j.ajcem.20140201.11

\begin{abstract}
Several damage rate occurs in liver during acute infections according to the infection agent. The exposure of the patient to two different infection causes at the same time is another situation complicating the diagnosis of infectious diseases. Hepatitis A virus and brucella are two factors that are observed from the childhood in developing countries as ours and presenting different pattern. Serological tests are used to benefit from differential diagnosis. In this study, the cases of hepatitis A and brucella co-infection in spite of the different contamination ways has been presented.
\end{abstract}

Keywords: Hepatitis a Virus, Brucellosis, Co-Infection

\section{Introduction}

Hepatitis A (HAV) is a frequently observed world-wide infection and almost contaminating by fecal-oral ways. It is widely observed in people living in bad hygienic conditions and with limited revenues and may create epidemic (1). Hepatitis A infection is the most frequent cause of childhood hepatitis (2). Hepatitis A infection is usually accompanied with inappetit, fatigue, nausea, vomiting, diarrhea, stomachache, constipation and rarely by meningeal irritation. In half of the cases, there is fever during 2-3 days. The liver is big and painful. Splenomegaly may be observed in $20 \%$ of the patients. Brucella infection presents a clinic pattern similar to viral hepatitis and is rarely accompanied with liver failure (3). Fever, hepatosplenomegaly, jaundice, medium increase in liver enzymes and pronounced increase in alkaline phosphatase are typical in brucella infection (4). The exposure of the patient to two different infection causes at the same time is another situation complicating the diagnosis of infectious diseases. The patterns leading to acute hepatitis are known but this situation covers the factors infecting in the same way. In this study, we presented two cases for which HAV and brucella co-infection have been diagnosed in spite of the different contamination ways and brucella co-infection have been diagnosed in spite of the different contamination ways.

\section{Case Report 1}

A four year-old male patient applied to the hospital for high fever, shivering, arthralgia, nausea, vomiting and stomachache, jaundice in skin and eyes and darkening in urine. There was no particularity on his and family history. There was no history of drug utilization lately. On physical examination, the general situation was normal, the consciousness was open. Sclera and skin were icteric. A painful and $5 \mathrm{~cm}$ liver and $3 \mathrm{~cm}$ spleen have been observed in abdomen examination. Traube was closed. The neurological examination was normal. Hemoglobin 12.6 $\mathrm{gr} / \mathrm{dl}$, leucocytes $8600 / \mathrm{mm}^{3}$, thrombocyte $178000 / \mathrm{mm}^{3}$ in laboratory analyses. The other values were as follows: Aspartate aminotransferase (AST) $1350 \mathrm{U} / \mathrm{L}$ (normal range: 8-46), alanine aminotransferase (ALT) $2218 \mathrm{U} / \mathrm{L}$ (normal range: 7-46), gamma glutamil transpeptidase (GGT) 176 U/L (normal range: 11-80), alkaline phosphatase (ALP) 483 
$\mathrm{U} / \mathrm{L}$, total bilirubin: $4,4 \mathrm{mg} / \mathrm{dL}$ and direct bilirubin: 1,7 $\mathrm{mg} / \mathrm{dL}$. Sedimentation $38 \mathrm{~mm} / \mathrm{h}$, C-reactive protein (CRP) $43 \mathrm{mg} / \mathrm{L}$ (normal range: $0-5 \mathrm{mg} / \mathrm{L}$ ), prothrombin time 15.1 seconds. Bilirubin was $3(+)$ and urobilinogen was $4(+)$ in urine analyses. In serological tests, anti-HAV IgM: positive, Anti-HAV IgG, HBV, hepatitis C virus, Ebstein-Barr virus markers and Gruber Widal was negative. Urine and blood cultures were normal. After a positive result in brucella tube agglutination in 1/640 titration, a treatment for the patient supposed to have HAV and brucella co-infection has bent started using streptomycin (40 mg/kg/day, intramuscular), rifampicin $(20 \mathrm{mg} / \mathrm{kg} / \mathrm{day}$, oral $)$ and trimethoprim $(10 \mathrm{mg} / \mathrm{kg} / \mathrm{day}$, oral $)$. At the third treatment day, the fever has been taken under control, vomiting was reduced, the oral intake increased and a pronounced amelioration has been observed in the general situation of the patient. At the third week of the treatment, the results were as follows: AST: $32 \mathrm{U} / \mathrm{L}$, ALT: $18 \mathrm{U} / \mathrm{L}$, total bilirubin: $1,1 \mathrm{mg} / \mathrm{dL}$, direct bilirubin $0,1 \mathrm{mg} / \mathrm{dL}$, sedimentation 10 $\mathrm{mm} / \mathrm{h}$ and CRP was $3 \mathrm{mg} / \mathrm{L}$. The patient has been discharged by completing the treatment to six weeks.

\section{Case Report 2}

A fifteen year-old male patient applied to the hospital for fatigue, inappetit, loss of weight, extensive muscle, body and bone pains and for the last 4-5 days high fever, vomiting, jaundice on skin and eyes and darkening in urine. On the physical examination, sclera and skin were icteric, the liver was $6 \mathrm{~cm}$ palpabl, smooth and painful and the spleen was $5 \mathrm{~cm}$ palpabl. Traube was closed. The neurological examination was normal. In laboratory analyses, the results were; hemoglobin $13.1 \mathrm{gr} / \mathrm{dl}$, leucocyte $18600 / \mathrm{mm}^{3}$ and thrombocytes $224000 / \mathrm{mm}^{3}$. The other values were as follows: AST: $1421 \mathrm{U} / \mathrm{L}, \mathrm{ALT}: 2345 \mathrm{U} / \mathrm{L}$, GGT:134 U/L, total bilirubin: $5,7 \mathrm{mg} / \mathrm{dL}$, direct bilirubin: 1,9 mg/dL, ALP: $676 \mathrm{U} / \mathrm{L}$, sedimentation $44 \mathrm{~mm} / \mathrm{h}$, CRP 65 $\mathrm{mg} / \mathrm{L}$ and PT: 15.7 seconds. Bilirubin was $2(+)$ and urobilinogen was $3(+)$ in urine analyses. In serological tests, the results were as follows anti-HAV IgM: positive, anti-HCV: negative. After a positive result of hepatitis A serology and the presence of observations for systemic infection, brucellosis and salmonella infections have been studied. After a positive result in brucella tube agglutination in 1/1280 titration, a treatment for the patient supposed to have HAV and brucella co-infection has been started using streptomycin (1x1 gr/day, intramuscular), doxycycline $(2 \times 100 \mathrm{mg} /$ day, oral) and rifampicin $(600$ $\mathrm{mg}$ /day oral). At the second treatment day, the fever has been taken under control, vomiting was reduced, the oral intake increased and a pronounced amelioration has been observed in the general situation of the patient, liver function tests and the bilirubin levels come back to normal. At the third week of the treatment, the results were as follows: AST $28 \mathrm{IU} / \mathrm{L}$, ALT $24 \mathrm{IU} / \mathrm{L}$, total bilirubin 0.7 $\mathrm{mg} / \mathrm{dL}$, direct bilirubin $0.2 \mathrm{mg} / \mathrm{dL}$, sedimentation: $13 \mathrm{~mm} / \mathrm{h}$, CRP: $4 \mathrm{mg} / \mathrm{L}$. The streptomycin treatment has been completed to 10 days. Rifampicin and doxycycline treatments have been completed to six weeks. The patient has been discharged by completing the treatment to six weeks.

\section{Discussion}

Hepatitis A virus and brucella infections diseases are frequently observed in children and adolescents. Brucellosis is observed endemically in the East and the South-East Anatolia of our country and 14644 cases have been reported in 2005 in our country $(5,6)$. The anti-HAV $\mathrm{IgG}$ rate showing the hepatitis A virus exposure is $59.5 \%$ in our city (7). While HAV was spread especially by fecal-oral way, brucella infection was spread mostly by infected dairy products by oral way, by inhaling the air in an environment where infected animals live, or by skin contact with infected animals or animal products (4).

The incubation period of hepatitis $A$ is between 15 and 50 days and has an average value of 28 days (4). Although there are many clinic types of hepatitis A and usually the disease has benign course. $90 \%$ of the cases under five years old are silent; but the symptoms increase with age. The fever rarely reaches $40{ }^{\circ} \mathrm{C}$ during the prodromal period of 1-7 days until the beginning of the jaundice, fatigue, slight headache, inappetit are observed. The first specific observation of the disease is the darkening of the urine color, pale or grey color of the feces, the yellow color of the sclera, the yellowing of the skin and mucosa. In most of patients $(50-80 \%)$ hepatomegaly was determined. The liver has smooth and rough marginated and these are sensible on palpation. Splenomegaly or lymphadenopathy may be observed in $4-9 \%$ of the patients. There is decrease in nausea, fatigue, inappetit with the development of jaundice. If the patient has fever, it decreases within few days $(8,9)$. Nausea, vomiting, diarrhea, constipation, jaundice and nonspecific gastrointestinal system observations such as stomachache as well as involvement of liver are observed in $70 \%$ of brucella cases (4). As the brucella agent continues to reproduce within phagocytic cells, it leads to involvement of liver which was the part of reticuloendothelial system and so that hepatosplenomegaly and disorders in liver function tests have been observed (8). In a study of Colmenero et al. (9) involvement of liver has been found at a rate of $2.5 \%$ among 530 cases. We observed hepatosplenomegaly and liver function disorder for our two cases. In both cases, while nausea, vomiting, jaundice, stomachache, fatigue and fever first let suppose hepatitis $\mathrm{A}$, but the absence of drug use in recent history and supportive observations in viral hepatitis serology, and with the long-lasting high fever, fatigue, inappetit and loss of weight, a systemic infection other than HAV infection has been supposed and brucellosis and salmonella infections frequent observed in our region have been studied. During analyses made on this purpose, anti-HAV IgM and brucella tube agglutination tests were positive and the hepatitis pattern has been supposed to be associated to 
the co-infection of HAV and brucella.

As brucella is an intracellular pathogen, only prolonged use of drugs that may affect the intracellular will be successful. Single antibiotic treatment is not recommended because clinic relapses may be observed (10). The drugs recommended for children are rifampicin, trimethoprim and streptomycin combination under eight years and doxycycline, rifampicin and streptomycin combination for eight years and more. The accepted treatment time for children is six weeks (11). As there was hypertransaminase in our cases, we did not give rifampicin at the beginning treatment. While administrating streptomycin and trimethoprim to our first case, we used streptomycin and doxycycline combination for the second case. At the tenth day of the treatment, as AST, ALT and bilirubin levels started to decrease, streptomycin has been stopped and rifampicin has been added to the treatment and be reached six weeks treatment. Two months after the end of the treatment, no relapse has been observed in the following.

\section{Conclusion}

As a result, although there are different contaminations ways, two factors with similar incubation times have led to synchronic disease. The cases have been presented because this situation is rare and no co-infection was expected. When the clinic situation of the patient may not be explained by only one disease in regions where brucella and hepatitis A are endemic, co-infections shall be studied.

\section{References}

[1] Ciocca M. Clinical course and consequences of hepatitis A infection. Vaccine 2000;18(1):71-4.

[2] Urganci N, Arapoglu M, Akyildiz B, Nuhoglu A. Neonatal cholestasis resulting from vertical transmission of hepatitis A infection. Pediatr Infect Dis 2003; 22: 381-2.

[3] Davison S. Acute hepatitis. Liver disease in children, Second edition, Oxford, Blackwell 2004; 92-106.

[4] Brucellosis. In: Pickering LK. Red Book: Report of the Committee on Infectious Diseases. 28th ed. Elk Grove Village, IL: American Academy of Pediatrics 2009; 237-39.

[5] Solmaz Çelebi, Mustafa Hacımustafaoğlu, Fatih Demirtaş, Enes Salı, Ülkü Gül, Mustafa Özel. Brucellosis in Childhood J Pediatr Inf 2011; 5: 59-62.

[6] Sarı E, Sarı İÖ, Say A, Güven F, Ulutaş AP. The evaluation of brucellosis in children in an endemic region of Turkey, Van. Gaziantep Med J 2013;19(1): 1-4

[7] Arabacı F, Demirli H .The seroprevalence of hepatıtıs A and B in children 6-10 years of age Journal of Infection 2005;19(4):457-60.

[8] Colmenero, J. D.; Reguera, J. M. Et all .Complications Associated with Brucella melitensis Infection: A Study of 530 Cases : Medicine (Baltimore). 1996 Jul;75(4):195-211

[9] Shen MW. Diagnostic and therapeutic challenges of childhood brucellosis in a nonendemic country. Pediatrics 2008; 121: 1178-83.

[10] Alavi SM, Alavi L . Treatment of brucellosis: a systematic review of studies in recent twenty years. Caspian J Intern Med 2013; 4 (2):636-41. 